\title{
openheart Long-term survival after surgical aortic valve replacement among patients over 65 years of age
}

\author{
Mansour T A Sharabiani, ${ }^{1}$ Francesca Fiorentino, ${ }^{1}$ Gianni D Angelini, ${ }^{1,2}$ \\ Nishith N Patel ${ }^{1}$
}

To cite: Sharabiani MTA, Fiorentino F, Angelini GD, et al. Long-term survival after surgical aortic valve replacement among patients over 65 years of age. Open Heart 2016;3:e000338. doi:10.1136/openhrt-2015000338

- Additional material is available. To view please visit the journal (http://dx.doi.org/ 10.1136/openhrt-2015000338)

Received 18 September 2015 Revised 18 December 2015 Accepted 21 January 2016

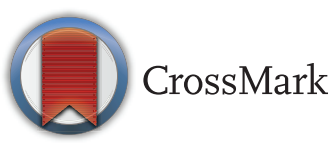

\footnotetext{
${ }^{1}$ Academic Cardiac Surgery, National Heart \& Lung Institute, Imperial College London, London, UK ${ }^{2}$ Bristol Heart Institute, University of Bristol, Bristol, UK
}

Correspondence to Dr Nishith N Patel; Nishith.patel@imperial.ac.uk

\section{ABSTRACT}

Objective: Surgical aortic valve replacement (AVR) remains the gold standard therapy for severe aortic stenosis. Long-term survival data following AVR is required. Our objective was to provide a detailed contemporary benchmark of long-term survival following AVR among elderly patients ( $\geq 65$ years) in the UK.

Methods: We conducted a retrospective cohort study of 1815 adult patients undergoing surgical AVR \pm coronary artery bypass graft (CABG) surgery at a single UK centre between 1996 and 2011. Our main outcome was patient survival, which was assessed by linkage to census records at the Office for National Statistics.

Results: The mean age of the cohort was $75( \pm 5.6)$ years. Patients in the AVR alone group had a slightly higher median survival of $10.9(95 \% \mathrm{Cl} 10.5$ to 11.8$)$ years than the AVR+CABG group which had a median survival of $9.6(95 \% \mathrm{Cl} 8.7$ to 10.1$)$ years ( $p=0.001$ of log-rank test (LRT) for equality of survivor functions). The presence of chronic kidney disease, severely impaired left ventricular function or being a current smoker were each associated with $a \geq 50 \%$ increased risk of long-term mortality. Comparison of our study cohort patients and the reference (operation year, age and gender matched) UK population suggested no difference in survival probability up to 8 years $(p=0.55)$. However, for longer periods of follow-up, the difference became increasingly significant $(p<0.0001)$.

Conclusions: Long-term survival following surgical AVR in patients over 65 years of age is excellent and up to 8 years is comparable to the matched general population.

\section{INTRODUCTION}

Aortic valve disease is the most common type of valvular heart disease in Europe and North America, occurring in $2-7 \%$ of the population over 65 years of age. ${ }^{1}{ }^{2}$ When untreated, symptom progression is rapid and lethal, with a median survival of $<2$ years in those with heart failure symptoms. ${ }^{34}$ Medical therapy is largely ineffective for the longterm management of aortic valve disease, and valve replacement remains the standard

\section{KEY QUESTIONS}

What is already known about this subject?

- Surgical aortic valve replacement (AVR) in elderly patients has excellent short-term and mid-term outcomes. The establishment of a robust surgical benchmark of long-term survival after open AVR is of increasing importance, particularly in the era of transcatheter aortic valve implantation (TAVI).

What does this study add?

- This study provides long-term survival data for patients over 65 years of age undergoing AVR and compares this to the expected survival of the general population. It demonstrates that longterm survival in this patient group is excellent.

How might this impact on clinical practice?

- Outcomes following AVR in elderly patients are excellent and, therefore, age should not be a factor when considering patients for surgical AVR. This study provides a benchmark for ongoing trials of TAVI in intermediate-risk patients with severe aortic stenosis.

of care in patients with an acceptable risk profile. Among the oldest patients and those with a high burden of comorbidities, the perioperative risk of surgical aortic valve replacement (AVR) is often perceived to outweigh the potential long-term benefits, with a perception of high operable risk accounting for $30 \%$ of all non-operated patients with symptomatic aortic stenosis (AS)..$^{5}$ Although the perioperative risk associated with AVR has been well studied, the long-term outcomes after open AVR have not been well described, making accurate assessment of the benefits of open AVR challenging in this population.

Transcatheter delivery of aortic valve prostheses offers a potential treatment option in high-risk patients and has been shown at 2-year follow-up to be superior to medical therapy in non-operable patients and 
non-inferior to open valve replacement in high-risk patients. ${ }^{6} 7$ As long-term transcatheter AVR outcomes accrue, the establishment of a robust surgical benchmark of long-term survival after open AVR is of increasing importance to inform prognosis and to aid clinical and economic evaluations of new technologies.

The objective of this study was therefore to describe in-hospital outcomes and long-term survival of patients undergoing surgical AVR, to compare their survival with the survival of the age-matched and gender-matched section of the general population and to assess the association between mortality and specific high-risk comorbidities.

\section{METHODS}

This was a retrospective cohort study of prospectively collected data from consecutive patients undergoing AVR at the Bristol Heart Institute, Bristol Royal Infirmary, UK, between April 1996 and December 2011. The study was approved by the Clinical Audit Committee of the University Hospitals Bristol National Health Service Foundation Trust to meet ethical and legal requirements, and individual consent was waived. The data collection form is entered in a database (Patient Analysis \& Tracking System; Dendrite Clinical Systems, London, UK) and includes five sections that are filled in consecutively by anaesthetists, surgeons, intensive care unit, high dependency unit and ward nurses. Data entry is periodically checked for accuracy by independent database managers.

Chronic kidney disease (CKD) was defined as a baseline serum creatinine of $\geq 200 \mu \mathrm{mol} / \mathrm{L}$. Chronic lung disease was defined as chronic obstructive pulmonary disease or asthma requiring bronchodilators or steroid therapy. Diabetes mellitus was defined as patients requiring oral hypoglycaemic agents or subcutaneous insulin therapy. Left ventricular (LV) systolic function was defined as normal (LV ejection fraction (LVEF) $\geq 52 \%$ ), mildly impaired (LVEF 41-51\%), moderately impaired (LVEF 30-40\%) and severely impaired (LVEF <30\%) according to the American Society of Echocardiography recommendations. ${ }^{8}$

\section{Study population}

The study cohort is a subset of the Bristol PATS database, which contains 21515 entries. The study cohort included elderly patients (aged $\geq 65$ years) who had undergone either elective or urgent AVR operation with or without coronary artery bypass graft (CABG) procedure. Records were excluded if they involved multiple valve procedures, other major non-valve-related operations (other than CABG), previous AVR and emergent or salvage operations.

\section{Patient subgroups}

Because long-term outcomes are expected to vary according to the burden of specific comorbidities, several patient subgroups were prospectively identified for analysis. For all analyses, patients were categorised by procedure type (eg, isolated $\mathrm{AVR}, \mathrm{AVR}+\mathrm{CABG}$ ) and age (65-69, 70-79, $\geq 80$ years). Other patient subgroups included European System for Cardiac Operative Risk Evaluation (EuroSCORE; low $\leq 5$, high $\geq 5$ ) and development of a postoperative complication.

\section{Study end point}

Patient survival, which was the primary outcome of interest for this study, was assessed by linkage to census records at the Office for National Statistics (ONS). Life status (mortality) information for all patients was obtained from the ONS up to 31 July 2013.

\section{Comparison with the operation year-matched, age-matched and gender-matched UK population}

To establish a comparative population-based reference survival curve, we generated a baseline Kaplan-Meier (KM) curve for an age-matched, gender-matched and year-matched patient population using the life tables of ONS. ${ }^{9}$ For each patient in our cohort, we used the annual mortality probabilities from the ONS life tables to run Monte Carlo (MC) simulations for that individual's survival, starting from the year of operation and advancing in yearly increments. ${ }^{10}$ The patient-level events were then aggregated across the cohort to generate a final aggregate $\mathrm{KM}$ curve, representing the expected survival behaviour of the matched general population. For each patient, $1000 \mathrm{MC}$ runs were performed to generate statistically sufficient events and produce a reliable baseline survival curve.

\section{Statistical analysis}

Descriptive statistics included mean \pm SD and percentages to describe patient and operative characteristics in two procedural groups, that is, those who underwent AVR alone and those who underwent AVR+CABG. These procedural groups were compared using t test or $\chi^{2}$ test as appropriate. Multiple logistic regression was used to estimate the predictors of in-hospital and 30-day mortality. Median survival times after surgery were measured for various strata of patients. Log-rank test (LRT) was used to evaluate the equality of the survivor functions. Multivariable Cox proportional hazards ( $\mathrm{CPH}$ ) model was used to estimate the HRs of long-term risk predictors of mortality. The assumption of proportionality of hazards was checked visually. For multiple logistic regression and CPH models, all the variables were included initially and stepwise backward elimination approach was used to arrive at the final models. The predictors which were examined for short-term and long-term risk models included age at operation, gender, smoking status, CABG procedure, LV function (LVF), history of chronic lung disease and/or CKD, extracardiac arteriopathy, preoperative arrhythmia, being under hypertensive and/or diabetic treatment as well as the EuroSCORE. We also 
performed univariate analysis and the $\mathrm{p}$ value threshold was Bonferroni adjusted to account for multiple testing.

Statistical analyses including generation of the aggregate $\mathrm{KM}$ curve using the simulated MC runs were performed using Stata V.11.2 for Windows (StataCorp, College Station, Texas, USA). MC simulations were performed using $\mathrm{R}$ programming language ( $\mathrm{R}$ Core Team. $\mathrm{R}$ : A language and environment for statistical computing. Vienna, Austria: R Foundation for Statistical Computing. 2014).

\section{RESULTS}

\section{Study population}

A cohort of 1815 adult patients underwent AVR for AS between 1996 and 2011, including 967 who underwent isolated AVR and 848 patients who underwent AVR with concomitant CABG surgery (figure 1 ). They had a mean age of $75( \pm 5.6)$ years, $1022(56 \%)$ were male patients, $38(2.1 \%)$ had CKD, $256(14.1 \%)$ had chronic lung disease and 107 (5.9\%) had severely impaired LVF. Patient and operative characteristics stratified by procedure are shown in table 1 . Thirty $(1.7 \%)$ patients were lost to long-term follow-up.

\section{In-hospital outcomes}

In-hospital outcomes are presented in table 2. A total of $68(3.8 \%)$ patients died in hospital or within 30 days following the operation. Of them, $27(1.5 \%)$ patients were in the AVR group and $41(2.3 \%)$ in the AVR+CABG group. EuroSCORE $>5$ was a significant predictor of in-hospital/30-day mortality (OR 1.4 (95\% CI 1.2 to $1.5), \mathrm{p}<0.0001)$. Postoperative reoperation for bleeding (8.6\% vs $7.9 \%, \mathrm{p}=0.048)$ and cerebrovascular accident (CVA) $(1.7 \%$ vs $0.7 \%, \mathrm{p}=0.040)$ was significantly higher in the AVR alone group compared to patients undergoing AVR+CABG. Conversely, the need for postoperative haemofiltration was lower in the AVR group than the AVR+CABG group, although this did not reach statistical significance $(1.8 \%$ vs $3.2 \%, \mathrm{p}=0.068$; table 2$)$. Results of the univariate analysis are shown in online supplementary table S1.

\section{Long-term survival after AVR}

Survival analysis included 5.4, 17.3 and 10950.55 years of median, maximum and total time at risk, respectively. In total, 707 (38.9\%) patients died during the follow-up period, of which 356 (19.6\%) underwent isolated AVR and $351(19.3 \%)$ underwent AVR+CABG. Patients in the AVR alone group had a slightly higher median survival of 10.9 (95\% CI 10.5 to 11.8 ) years than the AVR+CABG group which had a median survival of 9.6 (95\% CI 8.7 to 10.1 ) years $(\mathrm{p}=0.001$ of LRT for equality of survivor functions).

Median survival times in the AVR alone group across the age groups of ' $65-69$ ', ' $70-79$ ' and ' 80 or over' were 15.1, 10.6 and 6.3 years, respectively. In the AVR+CABG group, median survival times for the same age groups were 12.5, 9.6 and 6.4 years, respectively. The difference in survival of these six procedure age categories was significant $(p<0.0001$; figure 2$)$. Median survival times for AVR alone with no postoperative complication, AVR alone with any complication, AVR+CABG with no complication and AVR+CABG with any complication were 11.07, 7.02, 9.65 and 8.52, respectively. Median survival times stratified by procedural groups, procedure and age groups as well as procedure and EuroSCORE categories are shown in table 3 .

Table 4 shows HRs of the predictors of long-term mortality. Age at operation, chronic lung disease, hypertension, diabetes mellitus, extracardiac arteriopathy and preoperative arrhythmia were associated with increased
Figure 1 Bristol cardiac surgical database cohort development flow chart.

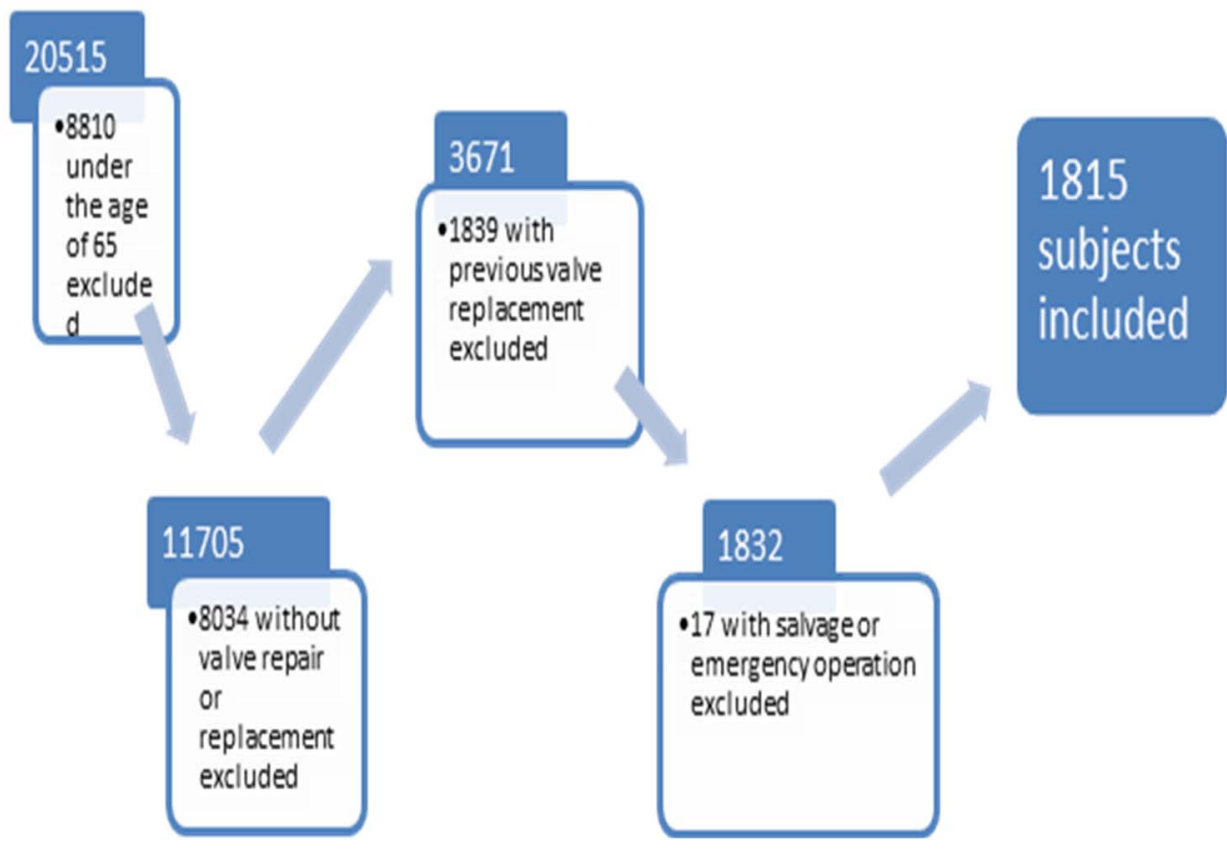


Table 1 AVR cohort characteristics stratified by procedure (AVR alone, AVR+CABG)

\begin{tabular}{lccr}
\hline Characteristics & Valve alone & Valve+other & p Value \\
\hline Number of patients & 967 & 848 & \\
Age at procedure & $74.8(5.6)$ & $75.4(5.7)$ & 0.02 \\
Male & $457(47.6 \%)$ & $565(66.6 \%)$ & $<0.0001$ \\
Cumulative bypass time & $92.8(27.3)$ & $125.6(38)$ & $<0.0001$ \\
Cumulative cross clamp time & $67(18.1)$ & $87.2(23.1)$ & $<0.0001$ \\
EuroSCORE & $6.8(1.9)$ & $7.3(2.1)$ & $<0.0001$ \\
Logistic EuroSCORE & $0.079(0.05)$ & $0.095(0.075)$ & $<0.0001$ \\
High EuroSCORE $(>5)$ & $720(74.5 \%)$ & $666(78.5 \%)$ & $<0.0001$ \\
Aortic valve gradient $(\mathrm{mm} \mathrm{Hg})$ & $55.1(41.1)$ & $43.8(37.0)$ & 0.53 \\
Aortic valve (mechanical) & $181(18.7 \%)$ & $149(18.2 \%)$ & 0.11 \\
Severely impaired left ventricular function & $49(5.1 \%)$ & $58(6.9 \%)$ & 0.68 \\
Chronic kidney disease $(\mathrm{SCr} \geq 200$ Hmol/L) & $19(2.0 \%)$ & $19(2.3 \%)$ & 0.45 \\
Chronic lung disease & $142(14.7 \%)$ & $114(13.4 \%)$ & $<0.0001$ \\
Number of grafts & $0.0(0.0 \%)$ & $1.8(1 \%)$ & $=0.21$ \\
\hline Aortic valve size $(\mathrm{mm})$ & & & \\
\hline 17 & $6(0.6 \%)$ & $8(0.9 \%)$ & \\
19 & $249(25.8 \%)$ & $186(21.9 \%)$ & \\
21 & $394(40.87 \%)$ & $333(40.1 \%)$ & \\
23 & $233(24.1 \%)$ & $226(26.6 \%)$ & \\
25 & $61(6.3 \%)$ & $71(8.4 \%)$ & \\
29 & $19(2.0 \%)$ & $18(2.1 \%)$ & \\
\hline
\end{tabular}

Mean (SD) or \%; t test and $\chi^{2}$ tests for comparing means and percentages, respectively.

AVR, aortic valve replacement; CABG, coronary artery bypass graft; EuroSCORE, European System for Cardiac Operative Risk Evaluation.

risk of long-term mortality. However, CKD, poor LVF or being a current smoker were each associated with a $\geq 50 \%$ increased risk of long-term mortality.

Comparison of our study cohort with the reference (operation year, age and gender matched) UK population suggested no difference in survival probability up to 8 years $(p=0.55)$. However, for longer periods of follow-up, the difference became increasingly significant $(\mathrm{p}<0.0001$; figure 3$)$. Moreover, the matched UK population shows significantly higher survival probability for women ( $p<0.0001$ for LRT). However, the survival advantage of women no longer existed for aortic valve surgery patients aged 65 years and over $(p=0.71$; figure 4$)$. We also stratified our analysis by procedural group. In the AVR alone group, survival was not different from the matched general population up to 9 years $(\mathrm{p}=0.11)$.

Table 2 Postoperative complications by procedure type

\begin{tabular}{lccc}
\hline $\begin{array}{l}\text { Postoperative } \\
\text { complication }\end{array}$ & AVR & AVR+CABG & p Value \\
\hline $\begin{array}{l}\text { Number of patients } \\
\text { In-hospital death }\end{array}$ & $27(1.5 \%)$ & $41(2.3 \%)$ & 0.022 \\
$\begin{array}{l}\text { Reoperation for } \\
\text { bleeding }\end{array}$ & $54(8.6 \%)$ & $67(7.9 \%)$ & 0.048 \\
$\begin{array}{l}\text { Permanent stroke } \\
\text { Haemofiltration }\end{array}$ & $15(1.7 \%)$ & $5(0.7 \%)$ & 0.040 \\
\hline $\begin{array}{l}\text { AVR, aortic valve replacement; CABG, coronary artery bypass } \\
\text { graft. }\end{array}$ &
\end{tabular}

However, in the AVR+CABG group, survival matched the general population only up to 7 years $(p=0.14)$. After these points, survival become significantly worse compared to their matched background population in both groups (see online supplementary figure S1).

\section{DISCUSSION \\ Main findings}

Our report provides a detailed contemporary benchmark of long-term survival following AVR among older patients in the UK. From our results, four important findings emerge. First, long-term survival following AVR among older patients is excellent and therefore age should not be a factor in the decision for surgery. Second, baseline CKD, severely impaired LVF and current smoking status indicate particularly poor longterm prognosis after surgical AVR. Third, development of a postoperative complication such as CVA, haemofiltration or re-exploration for bleeding reduced survival compared to patients who did not develop any complication. Fourth, the female survival advantage over men no longer exists in patients undergoing aortic valve surgery.

\section{Comparison with existing literature}

The expected survival of symptomatic patients with severe AS who do not have surgery is $1-4$ years. ${ }^{3}{ }^{4}$ Surgical AVR improves this dismal prognosis and, as we have shown in the present study, restores survival to that expected of an age-matched and gender-matched 
Figure 2 Long-term survival after (A) AVR and (B) AVR + CABG. Survival curves (Kaplan-Meier estimates) are presented with $95 \% \mathrm{Cls}$ and are stratified by age group. AVR, aortic valve replacement; $\mathrm{CABG}$, coronary artery bypass graft.
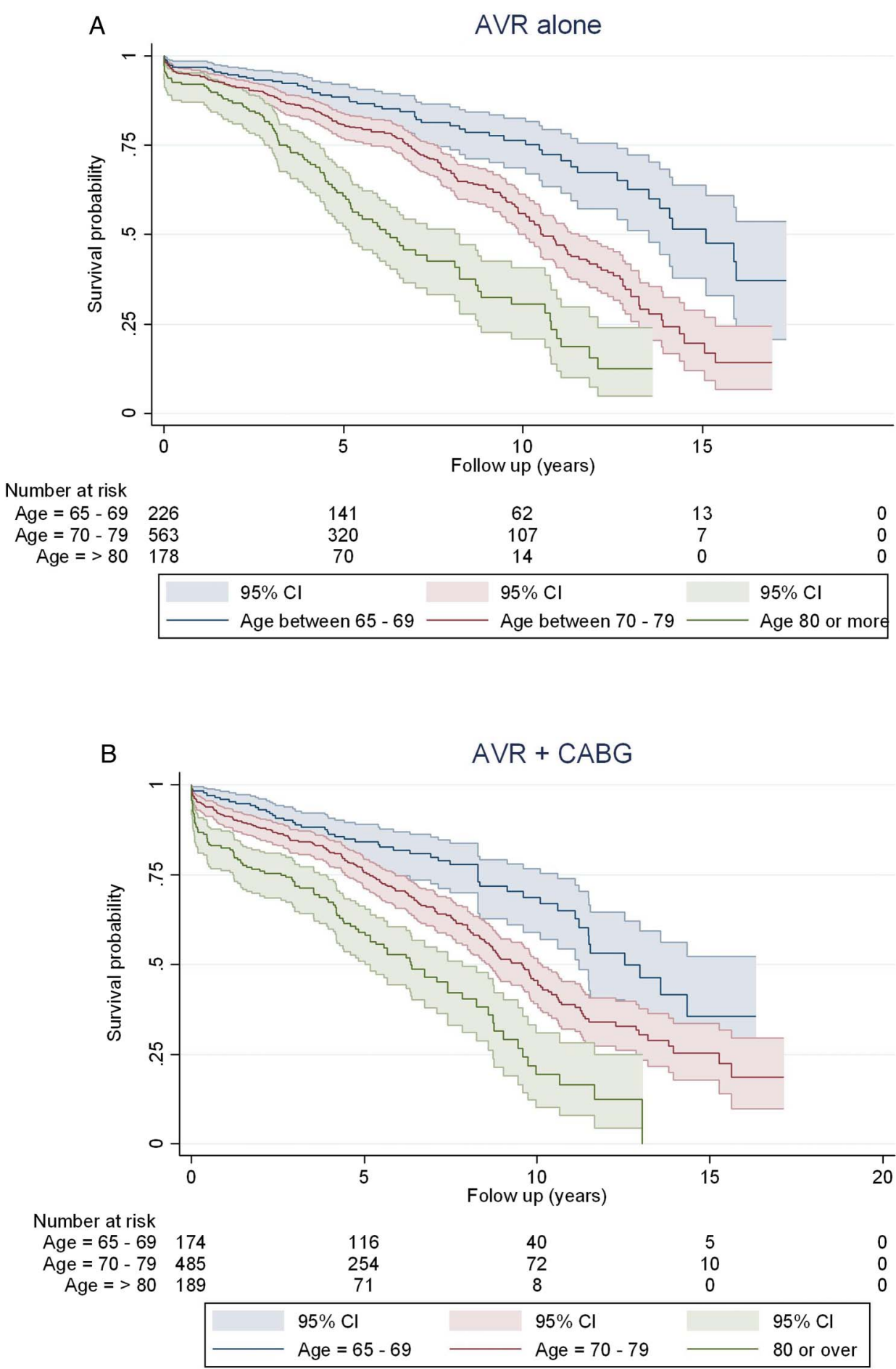

general population without AS at least up to 8 years of follow-up.

Our findings are consistent with previous reports by high-volume centres undertaking AVR in elderly patients. A report published using the Society of Thoracic Surgeons (STS) Adult Cardiac Surgery Database of over 145000 patients from over 1000 US centres found a median survival of 13, 9 and 6 years in patients undergoing isolated AVR aged 65-69, 70-79 and $\geq 80$ years of age, respectively. ${ }^{11}$ For patients undergoing AVR+CABG, median survival for the same age groups was 10,8 and 6 years. ${ }^{11}$ Similarly, baseline CKD, severely impaired LVF and being a current smoker have all been associated with poor long-term survival following surgical AVR. ${ }^{11} 12$

Transcatheter aortic valve implantation (TAVI) has emerged as an alternative to surgical AVR in the treatment of severe AS in inoperable or high-risk surgical candidates. The PARTNER 1B trial has demonstrated the significant short-term and mid-term survival and symptomatic benefit of TAVI compared to medical therapy in inoperable patients with severe $\mathrm{AS}^{7}{ }^{13}$ 
Table 3 Patient characteristics stratified by procedure (AVR alone, AVR+CABG), age, EuroSCORE and postoperative complication

\begin{tabular}{lcc}
\hline & Number of patients & Median survival (95\% Cl) \\
\hline Entire cohort & 1815 & $10.3(9.8$ to 10.6$)$ \\
By procedure groups & & \\
AVR alone & 967 & $10.9(10.5$ to 11.8$)$ \\
AVR+CABG & 848 & $9.6(8.7$ to 10.1$)$ \\
By procedure and age groups & 226 & \\
AVR alone (65-69) & 563 & $15.1(13.5, \ldots)$ \\
AVR alone (70-79) & 178 & $10.6(10.1$ to 11.6$)$ \\
AVR alone $(\geq 80)$ & 174 & $6.3(5.2$ to 8.2$)$ \\
AVR+CABG (65-69) & 485 & $12.5(11.2, \ldots)$ \\
AVR+CABG (70-79) & 189 & $9.6(8.6$ to 10.1$)$ \\
AVR+CABG ( $\geq 80)$ & & $6.4(5.2$ to 8.2$)$ \\
By procedure and EuroSCORE categories & 247 & \\
AVR alone; low EuroSCORE & 720 & $14.5(13.8, \ldots)$ \\
AVR alone; high EuroSCORE & 182 & $9.9(9.2$ to 10.6$)$ \\
AVR+CABG; low EuroSCORE & 666 & $13.2(10.7, \ldots)$ \\
AVR+CABG; high EuroSCORE & $8.7(8$ to 9.6$)$ \\
By procedure groups with or without any postoperative complications & \\
AVR alone; no complication & 881 & $11.07(10.50$ to 12.09$)$ \\
AVR alone; any complication & 86 & $7.02(5.43$ to 10.78$)$ \\
AVR+CABG; no complication & 743 & $9.65(8.76$ to 10.16$)$ \\
AVR+CABG; any complication & 105 & $8.52(6.44, \ldots)$ \\
\hline
\end{tabular}

*Postoperative haemofiltration, postoperative stroke and reoperation for bleeding.

AVR, aortic valve replacement; CABG, coronary artery bypass graft; EuroSCORE, European System for Cardiac Operative Risk Evaluation.

In high-risk surgical candidates (defined as an STS risk score of $\geq 10 \%$ ), the PARTNER 1A trial demonstrated TAVI to be equivalent to surgical AVR in terms of shortterm and mid-term mortality at 2 years. ${ }^{6}{ }^{14}$ However, TAVI did result in significantly higher rates of stroke, major vascular complications and paravalvular regurgitation compared to surgical AVR. As a result, international valve guidelines now recommend TAVI in patients who have a prohibitive surgical risk and a predicted post-TAVI survival of $>12$ months or who have a high surgical risk. ${ }^{15}$

Table 4 Predictors of long-term mortality (Cox regression survival analysis)

\begin{tabular}{|c|c|c|c|}
\hline \multicolumn{2}{|l|}{ Risk factor } & HR & p Value \\
\hline \multicolumn{2}{|l|}{ Age at operation } & 1.1 (1.1 to 1.1$)$ & 0.000 \\
\hline \multirow[t]{2}{*}{$\begin{array}{l}\text { Left ventricular } \\
\text { function }\end{array}$} & $\begin{array}{l}\text { (Moderately } \\
\text { impaired) }\end{array}$ & $1.2(1.0$ to 1.4$)$ & 0.119 \\
\hline & $\begin{array}{l}\text { (Severely } \\
\text { impaired) }\end{array}$ & $1.6(1.2$ to 2.1$)$ & 0.002 \\
\hline \multicolumn{2}{|l|}{ Lung disease } & $1.3(1.1$ to 1.6$)$ & 0.005 \\
\hline \multicolumn{2}{|c|}{ Chronic kidney disease } & 1.8 (1.2 to 2.8$)$ & 0.010 \\
\hline \multirow[t]{2}{*}{ Smoker } & (Former) & 1.1 (1.0 to 1.3$)$ & 0.185 \\
\hline & (Current) & $1.5(1.1$ to 2.1$)$ & 0.015 \\
\hline \multicolumn{2}{|c|}{ Antihypertensive treatment } & $1.2(1.0$ to 1.4$)$ & 0.028 \\
\hline \multicolumn{2}{|c|}{ Antidiabetic treatment } & $1.3(1.0$ to 1.6$)$ & 0.056 \\
\hline \multicolumn{2}{|c|}{ Arteriopathy (extracardiac) } & $1.4(1.1$ to, 1.9$)$ & 0.016 \\
\hline \multicolumn{2}{|c|}{ Arrhythmia (preoperative) } & $1.4(1.2$ to 1.7$)$ & 0.000 \\
\hline
\end{tabular}

Of concern, however, is that TAVI is being extended to low-risk and intermediate-risk surgical patients where no compelling evidence for its efficacy exists. For example, in Germany, the use of TAVI has exploded with 89 TAVIs performed per million population, the highest in

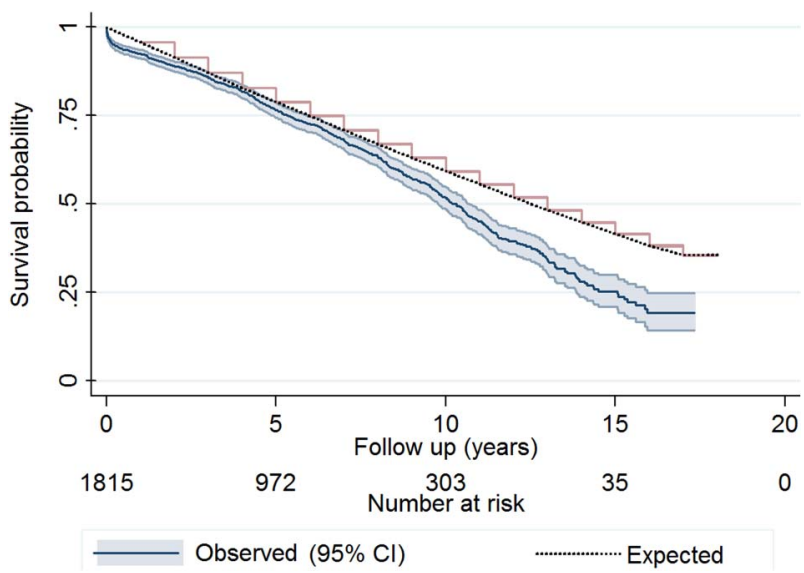

Figure 3 Comparison between Kaplan-Meier survival estimates of Bristol aortic valve surgery patients and the Monte Carlo-based generated Kaplan-Meier curve using the matched ONS population. It appears that for a follow-up period of $<8$ years, the difference between the survival estimates is not significant ( $p=0.55$ ) using log-rank test for equality of survivor functions. However, for longer periods of follow-up, the difference becomes increasingly significant with $p<0.0001$ for the entire follow-up period. ONS, Office for National Statistics. 


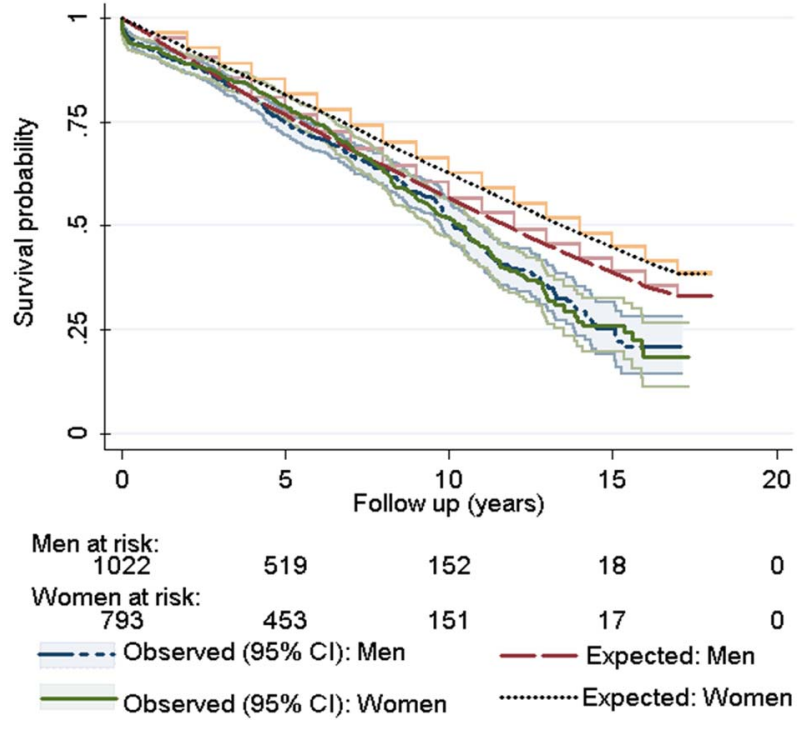

Figure 4 Comparison between Kaplan-Meier survival estimates of Bristol aortic valve surgery patients and the Monte Carlo-based generated Kaplan-Meier curve using the matched ONS population stratified by sex. Whereas the survival probability of women is significantly higher than men in the matched population $(\mathrm{p}<0.0001)$, no survival advantage exists for female gender among aortic surgery patients at the age of 65 years and over ( $p=0.71)$. ONS, Office for National Statistics.

Europe. ${ }^{16}$ This is compared to the UK where TAVI use is more regulated and therefore performs $<20$ implants per million population. ${ }^{16}$ Increasing number of observational studies report the equivalence of TAVI to surgical AVR in terms of in-hospital mortality in low-tointermediate-risk surgical patients. ${ }^{17-19}$ There are currently three ongoing randomised controlled trials (RCTs; SURTAVI, PARTNER IIA and UK TAVI) that are comparing TAVI and surgical AVR in intermediate-risk patients. The reports of these trials are eagerly awaited; however, the long-term efficacy of TAVI should not merely be measured by equivalence at $1-5$ years, but must demonstrate at least equivalence with surgical AVR at 10-15 years follow-up as provided in the current report.

\section{Strengths and limitations}

Our study has three major strengths. First, we used a prospectively maintained clinical database which is managed by several independent database managers who periodically check the accuracy of data entry. Second, we had a low attrition rate with over $98 \%$ of patients completing follow-up. Third, our clinical database is linked to the ONS in the UK. This provides accurate mortality data for individual patients as all deaths in the UK are reported to the ONS.

Our report has four limitations. First, we did not have a comparison group which would ideally be patients who have undergone TAVI with long-term follow-up data. However, at present, such data are not available.
Nevertheless, we compared our cohort survival with operation year-matched, age-matched and gendermatched general population. Second, we did not report the incidence of structural valve deterioration and the need for reoperation as these data are not readily available through our database. However, the deterioration of survival after 8 years of follow-up may be in part indicative of structural valve deterioration and the need for reoperation. Third, we did not conduct long-term functional assessment of patients which would be important for benchmarking. Last, we did not have cause of late mortality.

Our study highlights the need for national registries of surgical AVR and TAVI that provide detailed information on patient and procedural characteristics. Such registries must be linked to national mortality data so that longterm outcomes in patients with AS can be accurately reported.

\section{CONCLUSION}

Long-term survival following surgical AVR in patients over 65 years of age is excellent and is comparable to the matched general population especially up to 8 years. Baseline CKD, severely impaired LVF and current smoking status are associated with a particularly poor prognosis.

Acknowledgements The authors would like to thank Mr Alan Davies, clinical data manager, Bristol Royal Infirmary, for providing us access to the Bristol PATS database.

Contributors MTAS substantially contributed to the design of the work, full analysis and interpretation of results and drafting the manuscript. FF reviewed the study and drafted the manuscript. GDA served as scientific adviser, critically reviewed the study, contributed to the conception of the work and drafted the manuscript. NNP contributed to the conception and design of the work, interpretation of results and the acquisition of data, served as scientific adviser, drafted the manuscript.

Funding GDA and FF are supported by the British Heart Foundation; NNP is supported by the National Institute for Health Research. This research was supported by the NIHR Bristol Cardiovascular Biomedical Research Unit.

Competing interests None declared.

Patient consent Obtained.

Ethics approval The Clinical Audit Committee of the University Hospitals Bristol National Health Service Foundation Trust.

Provenance and peer review Not commissioned; externally peer reviewed.

Data sharing statement No additional data are available.

Open Access This is an Open Access article distributed in accordance with the terms of the Creative Commons Attribution (CC BY 4.0) license, which permits others to distribute, remix, adapt and build upon this work, for commercial use, provided the original work is properly cited. See: http:// creativecommons.org/licenses/by/4.0/

\section{REFERENCES}

1. lung B, Baron G, Butchart EG, et al. A prospective survey of patients with valvular heart disease in Europe: the Euro Heart Survey on Valvular Heart Disease. Eur Heart J 2003;24:1231-43.

2. Nkomo VT, Gardin JM, Skelton TN, et al. Burden of valvular heart diseases: a population-based study. Lancet 2006;368:1005-11.

3. Ross J Jr, Braunwald E. Aortic stenosis. Circulation 1968;38(1 Suppl):61-7. 
4. Horstkotte D, Loogen F. The natural history of aortic valve stenosis. Eur Heart J 1988;9(Suppl E):57-64.

5. lung B, Cachier A, Baron G, et al. Decision-making in elderly patients with severe aortic stenosis: why are so many denied surgery? Eur Heart J 2005;26:2714-20.

6. Kodali SK, Williams MR, Smith CR, et al. Two-year outcomes after transcatheter or surgical aortic-valve replacement. N Engl J Med 2012;366:1686-95.

7. Makkar RR, Fontana GP, Jilaihawi $\mathrm{H}$, et al. Transcatheter aortic-valve replacement for inoperable severe aortic stenosis. N Engl J Med 2012;366:1696-704.

8. Lang RM, Badano LP, Mor-Avi V, et al. Recommendations for cardiac chamber quantification by echocardiography in adults: an update from the American Society of Echocardiography and the European Association of Cardiovascular Imaging. J Am Soc Echocardiogr 2015;28:1-39.e14.

9. Office for National Statistics. National life tables, United Kingdom, 1980-82 to 2011-13. London, UK: Crown Publications, 2014.

10. Robert CP, Casella G. Monte Carlo statistical methods. Springer Texts in Statistics, 2004.

11. Brennan JM, Edwards $\mathrm{FH}$, Zhao $\mathrm{Y}$, et al. Long-term survival after aortic valve replacement among high-risk elderly patients in the United States: insights from the Society of Thoracic Surgeons Adult Cardiac Surgery Database, 1991 to 2007. Circulation 2012;126:1621-9.

12. Thourani VH, Myung R, Kilgo P, et al. Long-term outcomes after isolated aortic valve replacement in octogenarians: a modern perspective. Ann Thorac Surg 2008;86:1458-64.; discussion 64-5.
13. Kapadia SR, Tuzcu EM, Makkar RR, et al. Long-term outcomes of inoperable patients with aortic stenosis randomly assigned to transcatheter aortic valve replacement or standard therapy. Circulation 2014:130:1483-92.

14. Smith CR, Leon MB, Mack MJ, et al. Transcatheter versus surgical aortic-valve replacement in high-risk patients. N Engl J Med 2011;364:2187-98.

15. Nishimura RA, Otto CM, Bonow RO, et al. 2014 AHA/ACC Guideline for the management of patients with valvular heart disease: executive summary: a report of the American College of Cardiology/ American Heart Association Task Force on practice guidelines. Circulation 2014;129:2440-92.

16. Mylotte D, Osnabrugge RL, Windecker S, et al. Transcatheter aortic valve replacement in Europe: adoption trends and factors influencing device utilization. J Am Coll Cardiol 2013;62:210-9.

17. Lange R, Bleiziffer S, Mazzitelli D, et al. Improvements in transcatheter aortic valve implantation outcomes in lower surgical risk patients: a glimpse into the future. J Am Coll Cardiol 2012;59:280-7.

18. Piazza N, Kalesan B, van Mieghem N, et al. A 3-center comparison of 1-year mortality outcomes between transcatheter aortic valve implantation and surgical aortic valve replacement on the basis of propensity score matching among intermediate-risk surgical patients. JACC Cardiovasc Interv 2013;6:443-51.

19. Wenaweser P, Stortecky S, Schwander S, et al. Clinical outcomes of patients with estimated low or intermediate surgical risk undergoing transcatheter aortic valve implantation. Eur Heart J 2013;34: 1894-905 